\title{
Assessment of the level of agreement in the interpretation of plain radiographs of lumbar spondylosis among clinical physiotherapists in Ghana
}

\author{
Ajediran I Bello ${ }^{1 *}$, Eric K Ofori ${ }^{2}$, Oluwasegun J Alabi ${ }^{1}$ and David N Adjei ${ }^{3}$
}

\begin{abstract}
Background: Objective physical assessment of patients with lumbar spondylosis involves plain film radiographs (PFR) viewing and interpretation by the radiologists. Physiotherapists also routinely assess PFR within the scope of their practice. However, studies appraising the level of agreement of physiotherapists' PFR interpretation with radiologists are not common in Ghana.

Method: Forty-one (41) physiotherapists took part in the cross-sectional survey. An assessment guide was developed from findings of the interpretation of three PFR of patients with lumbar spondylosis by a radiologist. The three PFR were selected from a pool of different radiographs based on clarity, common visible pathological features, coverage body segments and short post production period. Physiotherapists were required to view the same PFR after which they were assessed with the assessment guide according to the number of features identified correctly or incorrectly. The score range on the assessment form was 0-24, interpreted as follow: 0-8 points (low), 9-16 points (moderate) and 17-24 points (high) levels of agreement. Data were analyzed using one sample t-test and fisher's exact test at $a=0.05$.

Results: The mean score of interpretation for the physiotherapists was $12.7 \pm 2.6$ points compared to the radiologist's interpretation of 24 points (assessment guide). The physiotherapists' levels were found to be significantly associated with their academic qualification $(p=0.006)$ and sex $(p=0.001)$. However, their levels of agreement were not significantly associated with their age group $(p=0.098)$, work settings $(p=0.171)$, experience $(p=0.666)$, preferred PFR view $(p=0.088)$ and continuing education $(p=0.069)$.

Conclusions: The physiotherapists' skills fall short of expectation for interpreting PFR of patients with lumbar spondylosis. The levels of agreement with radiologist's interpretation have no link with year of clinial practice, age, work settings and continuing education. Thus, routine PFR viewing techniques should be made a priority in physiotherapists' continuing professional education.
\end{abstract}

Keywords: Agreement, Plain radiographs, Interpretation, Clinical physiotherapists

\section{Background}

Spondylosis is a degenerative disease which can occur at any level of the spine but commonly detected at the cervical and lumbar regions [1]. It is characterized by a series of degenerative changes at the spinal end-plates, vertebral bodies and intervertebral discs with consequent

\footnotetext{
* Correspondence: iabello@chs.edu.gh

'Department of Physiotherapy, School of Allied Health Sciences, College of Health Sciences, University of Ghana, Accra, Ghana

Full list of author information is available at the end of the article
}

formation of osteophytes and sclerosis [2]. The clinical deficits of lumbar spondylosis can range from mild to severe pain and from minimal to maximum disability with significant impact on work productivity and the quality of life of the sufferers $[3,4]$.

Plain film radiograph (PFR) is one of the common imaging techniques used to confirm the diagnosis of lumbar spondylosis by the radiologists in most clinical settings in Ghana and it remains the mainstay in most developing African countries given its availability and cost effectiveness.

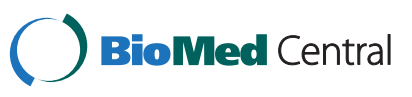


Studies assessing the level of agreement of interpretation of imaging techniques among allied health professionals have been documented in literature. For instance, the outcome of meta-analysis on the degree of agreement between radiographers and radiologists to determine the radiographers' accuracy in radiographic reports revealed accuracy level of the radiographers at $92.6 \%$ and $97.7 \%$ sensitivity and specificity respectively while nurses working at remote units also showed their respective accuracy levels at $96 \%$ for sensitivity and $87 \%$ for specificity $[5,6]$. Although the previous studies have assessed the interpretation of PFR among other allied health professionals, studies on agreement of physiotherapists in the interpretation of PFR are not readily available.

Based on anedoctal observation from the Ghanaian health care setting, at least two orthogonal PFR views (Anterio-posterior and lateral) are commonly examined in the preliminary assessment of patients with lumbar spondylosis by the physicians and orthopaedic specialists. Eventhough the interpretation of PFR remains within the purview of the radiologists, physiotherapists often perform this task either as extended scope of practice or as routine procedure during objective assessment. With the emergence of physiotherapy practice from under the cover of traditional referral system to selfreferral methods of health care delivery particularly in wellness and musculoskeletal fields, Ghanaian physiotherapists are required to extend their horizon to be relevant in the ongoing global health reform [7]. Correct interpretation of PFR among physiotherapists becomes necessary in order to identify possible contra-indications to some physiotherapy techniques and/or modification of treatment plans accordingly to change the natural course of the presented conditions [8].

Given the growing reliance on radiographic imaging and the evolvement of first contact practice in some allied health professionals, it is necessary to appraise the skills of the relevant available health care professionals in the interpretation of imaging techniques. This study therefore determined the level of agreement in the interpretation of PFR of lumbar spondylosis between the physiotherapists and radiologists in Ghana.

\section{Methods}

\section{Participants}

Forty-one (41) clinical physiotherapists participated in this cross-sectional survey. They were recruited through sample of convenience from the Government hospitals and private physiotherapy clinics located at four of the ten Regions in Ghana. Clinical physiotherapists who were registered members of Ghana Physiotherapy Association and those who had practiced for at least one (1) year were included in the study. Retired physiotherapists and those in academics were excluded.

\section{Design of an assessment guide}

Three separate PFR (two antero-posterior and one lateral views) were selected from a pool of PFR of patients undergoing physiotherapy for lumbar spondylosis at the selected hospitals and clinics. The selection was based on the clarity of the films, availability of common lumbar spondylosis pathology, coverage of peripheral body segments (bilateral pelvis and hips), and post production period not exceeding three (3) months. The selected films were shown to an experienced independent radiologist who in turn identified the pathological features and listed them as gold standard to serve as an assessment guide (Appendix 1). The listed pathological features were found to be comparable and consistent to that obtained from twenty retrospective radiologists' reports on patients with lumbar spondylosis. A total of 24 features were identified by the radiologist from three PFR with each consisting 8 features. The assessment guide was subjected to test re-tests reliability among seven experienced radiologists whose reports were not included in the retrospective reports to scrutinize the list. A good internal consistency of 0.79 Chrombach's alpha value was obtained through the evaluation process [9]. Correct identification of a pathological feature attracts one (1) point while wrong identification or non-identification attracts 0 point. The score range on the form is $0-24$ in which the minimum obtainable score is zero ( 0 ) while the maximum obtainable score is 24 . The scoring is interpreted as follow: $0-8$ points (low level of agreement), 9-16 points (moderate level of agreement) and 17-24 points (high level of agreement).

\section{Procedure}

The Ethics and Protocol Review Committee of the School of Allied Health Sciences, University of Ghana approved the proposal for this study. An information sheet containing the title and the intent of the study was made available to the participants and their written consents were obtained. A self-designed data capturing form was used to obtain demographic data such as age, sex and academic qualification and clinical data including number of years of clinical experience, work settings and the number of continuing professional development (CPD) programme attended in the last 5 years (Appendix 2). The three plain film radiographs (PFR) of lumbar spondylosis from which the assessment guide was developed were viewed by the physiotherapists in the presence of the researchers and in no particular order to avoid stereo-typed interpretation. They were required to list the identifiable patho-anatomical features observed in the PFR. A time commitment of 30 minutes was expected of the participants for the completion of the entire procedure. On completion of the interpretation and documentation process, the researchers collected the findings and evaluated each physiotherapist using the assessment guide. 


\section{Data analysis}

Data were analyzed using the SPSS version 19.0 software. Descriptive statistics of frequency, percentage, mean and standard deviation were used to summarize the data. One sample Kolmogorov-Smirnov test was explored to test the data for normalcy. Comparison of PFR interpretation between the physiotherapists and the radiologist was tested with one sample t test while Fisher's exact test was used to determine the associations between levels of agreement and the physiotherapists' demographic and clinical variables at alpha level of 0.05 .

\section{Results}

Forty-one (41) physiotherapists participated in this study comprising 17 (41.5\%) males and 24 (58.5\%) females. The demographic and clinical profiles of the participants are presented in Table 1. Most physiotherapists, 25 (61\%) were within the age range 26-30 years and 36 (88\%) of them hold bachelor's degree while five (12\%) had masters' degree. The study also showed that majority of the physiotherapists 24 (58.5\%) worked in teaching hospitals while $3(7.3 \%)$ worked in general hospital. Twenty-five (61\%) had been practicing for less than or a total of four (4) years as compared to 16 (39\%) who had worked for 5 to 9 years. Twenty-four (58.6\%) of the physiotherapists had attended less than or a total of two continuing professional development (CPD) programmes while 6 (14.6\%) had attended less than or a total of 6 CPD programmes.

Results of the categorical levels of assessment shows that $4(9.8 \%)$ physiotherapists scored between 0 and 8 points (Low); 35 (85.4\%) scored between 9 and 16 points (Moderate); 2 (4.9\%) scored between 17 and 24 points (High). The levels of agreement were significantly associated with academic qualification (0.006) and the sex ( $\mathrm{p}=$ 0.001 ) of the physiotherapists. However, the levels of agreement were not significantly associated with the age group $(\mathrm{p}=0.098)$, work setting $(\mathrm{p}=0.171)$, year of clinical practice $(p=0.666)$, preferred PFR views $(p=0.088)$ and the number of CPD attended ( $\mathrm{p}=0.069)$ (Table 2).

Exploration of one sample Kolmogorov-Smirnov test for normalcy of data shows no significant difference in the dataset distribution $(p=0.207)$ thereby justifying the adoption of one sample $t$ test analysis. The mean score of agreement $(12.7 \pm 2.6)$ for the physiotherapists was significantly lower $(\mathrm{p}=0.001)$ than the gold standard point of 24 (Radiologist's score).

\section{Discussion}

The main focus of this study was to assess the level of agreement of interpretation of plain radiographs (PFR) between the radiologists and physiotherapists in Ghana. The mean score of interpretation of the physiotherapists compared to that of the radiologists in this study was 12.7 (approximately $50.0 \%$ of the total point) which was
Table 1 Demographic and clinical profiles of the physiotherapists

\begin{tabular}{|c|c|c|}
\hline Variable & Number & Percentage \\
\hline \multicolumn{3}{|l|}{ Sex } \\
\hline Male & 17 & 41.5 \\
\hline Female & 24 & 58.5 \\
\hline Total & 41 & 100 \\
\hline \multicolumn{3}{|l|}{ Age group (years) } \\
\hline $21-25$ & 1 & 2.4 \\
\hline $26-30$ & 25 & 61.0 \\
\hline $31-35$ & 11 & 26.8 \\
\hline $36-40$ & 2 & 4.9 \\
\hline $41-45$ & 1 & 2.4 \\
\hline $46-50$ & 1 & 2.4 \\
\hline Total & 41 & 100.0 \\
\hline \multicolumn{3}{|c|}{ Academic qualification } \\
\hline BSC. & 36 & 87.8 \\
\hline MSc. & 5 & 12.2 \\
\hline Total & 41 & 100 \\
\hline \multicolumn{3}{|c|}{ Years of clinical practice } \\
\hline $0-4$ & 25 & 61.0 \\
\hline $5-9$ & 16 & 39.0 \\
\hline Total & 41 & 100.0 \\
\hline \multicolumn{3}{|l|}{ Work setting } \\
\hline Regional hospital & 10 & 24.4 \\
\hline Teaching hospital & 24 & 58.5 \\
\hline General hospital & 3 & 7.3 \\
\hline Private hospital & 4 & 9.8 \\
\hline Total & 41 & 100.0 \\
\hline \multicolumn{3}{|c|}{ CPD programme attendance } \\
\hline $0-2$ & 24 & 58.6 \\
\hline $3-5$ & 11 & 26.8 \\
\hline$\geq 6$ & 6 & 14.6 \\
\hline Total & 41 & 100.0 \\
\hline \multicolumn{3}{|c|}{ Preference of radiograph view } \\
\hline Antero-posterior & 5 & 12.2 \\
\hline Lateral & 15 & 36.6 \\
\hline Neither & 21 & 51.2 \\
\hline Total & 41 & 100.0 \\
\hline
\end{tabular}

Key: $\mathrm{CPD}=$ Continuing professional development.

statistically lower than the required scores. This finding falls short of expectation giving the high agreement of other health care professionals with the radiologists in the previous studies [5,6]. For instance, Brealey et al. reported high accuracy levels for radiographers at $92.6 \%$ and $97.7 \%$ sensitivity and specificity respectively [5] while Benger submitted that nurses working in remote units had 
Table 2 Fisher's exact analysis for the associations between the physiotherapists' levels of agreement of PFR interpretation and their clinical and demographic characteristics

\begin{tabular}{|c|c|c|c|c|}
\hline Variables & Low n (\%) & Moderate $\mathrm{n}(\%)$ & High n (\%) & Fisher's exact test $p$ value \\
\hline \multicolumn{5}{|l|}{ Age (years) } \\
\hline $21-25$ & $0(0.0)$ & $1(100)$ & $0(0.0)$ & \multirow[t]{6}{*}{0.098} \\
\hline $26-30$ & $2(8.0)$ & $20(80.0)$ & $3(12.0)$ & \\
\hline $31-35$ & $0(0.0)$ & $11(100)$ & $0(0.0)$ & \\
\hline $36-40$ & $0(0.0)$ & $2(100)$ & $0(0.0)$ & \\
\hline $41-45$ & $0(0.0)$ & $0(0.0)$ & $1(100)$ & \\
\hline $46-50$ & $0(0.0)$ & $1(100)$ & $0(0.0)$ & \\
\hline \multicolumn{5}{|l|}{ Qualification } \\
\hline B.SC & $2(5.5)$ & $32(88.8)$ & $2(5.5)$ & \multirow[t]{2}{*}{$0.006^{*}$} \\
\hline M.Sc & $0(0.0)$ & $3(60.0)$ & $2(40.0)$ & \\
\hline \multicolumn{5}{|l|}{ Work setting } \\
\hline Regional hospital & $1(10.0)$ & $8(80.0)$ & $1(10.0)$ & \multirow[t]{4}{*}{0.171} \\
\hline Teaching hospital & $1(4.1)$ & $21(87.5)$ & $2(8.3)$ & \\
\hline General hospital & $0(0.0)$ & $2(66.7)$ & $1(33.4)$ & \\
\hline Private hospital & $0(0.0)$ & $4(100)$ & $0(0)$ & \\
\hline \multicolumn{5}{|l|}{ Years of practice } \\
\hline $0-4$ & $2(8.0)$ & $22(88.0)$ & $1(4.0)$ & \multirow[t]{2}{*}{0.666} \\
\hline $5-9$ & $0(0.0)$ & $13(81.2)$ & $3(18.7)$ & \\
\hline \multicolumn{5}{|l|}{ No of CPD attended } \\
\hline $0-2$ & $1(4.2)$ & $22(91.7)$ & $1(4.2)$ & \multirow[t]{3}{*}{0.069} \\
\hline $3-5$ & $1(9.0)$ & $9(81.8)$ & $1(9.0)$ & \\
\hline$\geq 6$ & $0(0.0)$ & $4(66.7)$ & $2(33.4)$ & \\
\hline \multicolumn{5}{|l|}{ Sex } \\
\hline Male & $0(0.0)$ & $4(23.5)$ & $13(76.4)$ & \multirow[t]{2}{*}{$0.001^{*}$} \\
\hline Female & $2(8.4)$ & $0(0.0)$ & $22(91.7)$ & \\
\hline \multicolumn{5}{|l|}{ Preferred view } \\
\hline Anterio-posterior view & $1(20.0)$ & $4(80.0)$ & $0(0.0)$ & \multirow[t]{3}{*}{0.088} \\
\hline Lateral view & $0(0.0)$ & $13(86.7)$ & $2(13.4)$ & \\
\hline Both & $1(4.7)$ & $18(85.7)$ & $2(9.5)$ & \\
\hline
\end{tabular}

Key: *Significant at $\mathrm{p}<0.05$.

$96 \%$ sensitivity and $87 \%$ specificity in the interpretation agreement [6]. These variations might not be unconnected with the different settings in which the studies were conducted.

In addition, approximately $85.4 \%$ of the physiotherapists' scores were within the moderate range (9-16 points) which implies that majority of the participants' performances were within the average in PFR interpretation. Although PFR viewing is a common routine procedure in physiotherapy, it seems little priority has been placed on its techniques in the series of their continuing education programmes. Presumably, they might have acquired their rudimentary skills through personal efforts and interest. These speculations may be justifiable given the crops of young generation of the practicing physiotherapists in Ghana.
In the same vein, the levels of agreement in the interpretation of PFR by the physiotherapists' were significantly associated with their academic qualification and sex. Most of the physiotherapists were first degree holders implying that they were still at the minimum entry level of the profession as stipulated by the World Confederation for Physical Therapy [10]. Post-graduate training programme in the field of physiotherapy is yet to take off in Ghana, thus the few physiotherapists with masters degree had to divert to other fields that may not directly impact on their clinical proficiency. The link between gender and level of agreement may be ascribed to the relative proportion of the sampled male and female physiotherapists in this study. Contrarily, the age, work settings, years of clinical practice and the preferred PFR views have no significant 
impact on the level of agreements. These findings suggest that the physiotherapists' disposition towards PFR viewing rather than the selected clinical variables are the influencing factors. Further, specialty physiotherapy training and practice in Ghana are yet to be established, hence daily practice cuts across the branches of the profession without specific emphasis on orthopaedics-related cases where $\mathrm{x}$-ray viewing and interpretation are mostly needed.

A shift in the focus of health care delivery from the hospital to the community, are placing increased demands on physiotherapists to embrace primary-care systems. Available evidence suggests that physiotherapists' involvements in the primary health care setting are beneficial to patients suffering from musculoskeletal problems such as arthritis and low back pain [11]. Indeed, the convergence of rising health care costs and physician shortages have made health care transformation a priority in many developing countries resulting in the emergence of new models of care that often involve the extension of the scope of practice for most allied health professionals. Physiotherapists in extended scope roles must emerge as key providers in such new models, especially in settings providing services to patients with musculoskeletal disorders [12].

\section{Limitation of the study}

The findings from this study are limited by the use of very few plain film radiographs of patients suffering from lumbar spondylosis with which the participants were assessed. Sampling over sufficient numbers of patients' $x$-rays would have ensured external validity of the results. These observations should be the focus of the future study.

\section{Conclusions}

We conclude that the sampled Ghanaian physiotherapists had disproportionate level of agreement in the interpretation of PFR of patients with lumbar spondylosis compared to that of the Radiologist. The sex and academic qualification of the sampled physiotherapists had significant bearing on their level of agreement. The outcomes of this study thus underscore the urgent need to include basic training in the interpretation of plain radiographs into the continuing professional development programme of physiotherapists in Ghana.

\section{Appendix 1}

\section{Assessment guide}

The underlisted three plain film radiographs (PFR) A, B, and $\mathrm{C}$ contain the common degenerative features found in patients diagnosed with lumbar spondylosis in two views (anterio-posterior and lateral):

PFR A: Lumbar spine only (anterio-posterior view)

PFR B: Lumbar spine + Pelvis (anterio-posterior view)

PFR C: Lumbar spine only (Lateral view)
The following (8) features were the pathological features found in each of the PFR.

1. Marginal osteophytes on lumbar vertebrae

2. Decreased vertebral body height

3. Decreased lumbar intervertebral disc space

4. End plate sclerosis of articular surfaces in the lumbar region

5. Scoliotic lumbar vertebrae

6. Exaggerated lumbar lordosis

7. Straightening of the lumbar spine (reduced normal lumbar lordosis)

8. Vacuum phenomenon

Mark each correctly identified pathological feature as 1 point and wrong identification or non-identification as 0 point. The total score is 24 ranging from $0-24$ in which the minimum obtainable score is zero (0) while the maximum obtainable score is 24 . The scoring is interpreted as follow: 0-8 scores (low level of agreement), 9-16 scores (moderate level of agreement) and 17-24 scores (high level of agreement).

\section{Appendix 2}

\section{Data capturing form}

Instruction: Kindly supply the following information as applicable to you

Section A: Demographics

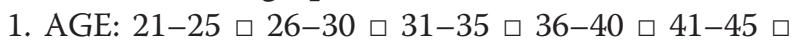
46-50 $\square$ 51-55 $\square 55 \square$

2. SEX: Male $\square$ Female $\square$

3. ACADEMIC QUALIFICATIONS (kindly tick more than one if applicable)

Diploma $\square$ B. Sc. $\square$ M. Sc. $\square$ Ph. D $\square$

Others (specify).

1. Are you a registered member of the Ghana Association of Physiotherapists?

Yes $\square$ No $\square$

\section{Section B: Clinical variables}

1. In which of the following work settings do you practise?

Teaching Hospital $\square$ General Hospital $\square$ Regional Hospital $\square$ Private $\square$

1. How many years of Clinical experience (excluding internship) do you have?

2. How many Orthopaedics related Continuous Professional Development (C.P.D.) programme (workshop, seminar, conference e.t.c.) have you attended in the last 5 years?

3. Which view of the plain Radiograph would you request for when assessing a patient suspected to have Lumbar spondylosis? Antero-Posterior $\square$ Lateral $\square$ 


\section{Authors' contributions}

$A B$ responsible for the design of the manuscript for intellectual presentation. He also contributed to the collection, management, analysis and interpretation of data. EO, assisted in the collection, management, analysis and interpretation of data. OA, participated in the collection of data and final editing of the manuscript. DA participated in data interpretation and analysis. All authors read and approved the final manuscript.

\section{Acknowledgement}

We sincerely acknowledge the immense contributions of the Radiologists from the selected hospitals for their readiness to assist in the design of the assessment form. Special tribute also goes to Dr Harriet Obeng for her time in interpreting the three plain film radiographs used in developing the assessment guide.

\section{Author details}

'Department of Physiotherapy, School of Allied Health Sciences, College of Health Sciences, University of Ghana, Accra, Ghana. ${ }^{2}$ Department of Radiography, School of Allied Health Sciences, College of Health Sciences, University of Ghana, Accra, Ghana. ${ }^{3}$ Department of Medical Laboratory Sciences, School of Allied Health Sciences, College of Health Sciences, University of Ghana, Accra, Ghan.

Received: 26 December 2012 Accepted: 24 March 2014

Published: 29 March 2014

\section{References}

1. Gibson JNA, Waddell G: Surgery for degenerative lumbar spondylosis. Spine 2005, 20:2312-2320.

2. Emery SE, Ringus VM: Osteoarthritis of the Spine. In Osteoathritis: Diagnosis and Medical/Surgical Management. 4th edition. Edited by Moskowitz RW, Altman RD, Hochberg MC, Buckwalter JA, Goldberg VM. Philadelphia: Lippincott Williams and Wilkins; 2007:427-452.

3. Haldeman S, Chapman SD, Peterson DM: Diagnostic Imaging of Lumbar Dics Herniations. In Guidelines for Chiropractic Quality Assurance and Practice Parameters. Edited by Haldeman S, Chapman SD, Peterson DM. Gaithersburg MD: Aspen; 1995.

4. Middleton K, Fish DE: Lumbar spondylosis: clinical presentation and treatment approaches. Curr. Rev Musculoskelet Med 2009, 2:94-104.

5. Brealey S, Scally A, Halm S, Thoma N, Godfrey C: Accuracy of Radiographers' plain radiograph reporting in clinical practice: a meta-analysis. $J$ Clin Radiol 2005, 60:232-241.

6. Benger JR: Can nurses working in remote units accurately request and interpret radiographs? Emerg Med J 2002, 19(1):68-70.

7. Litchfield R, MacDougall C: Professional issues for physiotherapists in familty-centered and community-based settings. Aust J Physiother 2002, 48:105-112.

8. Jarvik JG, Hollingworth W, Martin B, Emerson SS, Gray DT, Overman S, Robinson D, Staiger T, Wessbecher F, Sullivan SD, Kreuter W, Deyo RA: Rapid magnetic resonance imaging versus radiographs for patients with Low back pain: a randomized controlled trial. J Am Med Assoc 2003, 4 289(21):2810.

9. Tavacol M, Dennick R: Making sense of Cronbach's alpha. Int J Med Educ 2011, 2:53-55. doi:10:511/ijme.4dfb.8dfd.

10. World Confederation for Physical Therapy (2012): Entry Education Programmes in Physical Therapy. WCPT Reports; 2012. Available online at http://www.wcpt.org.

11. Cott CA, Mandoda S, Landry MD: Models of integrating physical therapists into family health teams in Ontario, Canada: challenges and opportunities. Physiother Can 2011, 63(3):265-275. doi:10.3138/ptc.2010-01.

12. Desmeules F, Roy JS, Woodhouse L: Advanced practice physiotherapy in patients with musculoskeletal disorders: a systematic review. BMC Musculoskelet Disord 2012, 13:107.

doi:10.1186/1471-2342-14-13

Cite this article as: Bello et al: Assessment of the level of agreement in the interpretation of plain radiographs of lumbar spondylosis among clinical physiotherapists in Ghana. BMC Medical Imaging 2014 14:13.

\section{Submit your next manuscript to BioMed Central and take full advantage of:}

- Convenient online submission

- Thorough peer review

- No space constraints or color figure charges

- Immediate publication on acceptance

- Inclusion in PubMed, CAS, Scopus and Google Scholar

- Research which is freely available for redistribution 